\title{
Waste Tire Particles and Gamma Radiation as Modifiers of the Mechanical Properties of Concrete
}

\author{
Eduardo Sadot Herrera-Sosa, ${ }^{1}$ Gonzalo Martínez-Barrera, ${ }^{2}$ \\ Carlos Barrera-Díaz, ${ }^{3}$ and Epifanio Cruz-Zaragoza ${ }^{4}$ \\ ${ }^{1}$ Facultad de Química, Universidad Autónoma del Estado de México, Paseo Colón Esquina Paseo Tollocan s/n, \\ 50180 Toluca, MEX, Mexico \\ ${ }^{2}$ Laboratorio de Investigación y Desarrollo de Materiales Avanzados (LIDMA), Facultad de Química, \\ Universidad Autónoma del Estado de México, km 12 de la Carretera Toluca-Atlacomulco, San Cayetano, 50200 Toluca, MEX, Mexico \\ ${ }^{3}$ Centro Conjunto de Investigación en Química Sustentable, Universidad Autónoma del Estado de México, \\ Universidad Nacional Autónoma de México (UAEM-UNAM), Carretera Toluca-Atlacomulco km 14.5, Unidad El Rosedal, \\ 50200 Toluca, MEX, Mexico \\ ${ }^{4}$ Unidad de Irradiación y Seguridad Radiológica, Instituto de Ciencias Nucleares, Universidad Nacional Autónoma de México, \\ A.P. 70-543, 04510 Mexico City, DF, Mexico
}

Correspondence should be addressed to Gonzalo Martínez-Barrera; gonzomartinez02@yahoo.com.mx

Received 15 November 2013; Accepted 27 January 2014; Published 6 March 2014

Academic Editor: Osman Gencel

Copyright (C) 2014 Eduardo Sadot Herrera-Sosa et al. This is an open access article distributed under the Creative Commons Attribution License, which permits unrestricted use, distribution, and reproduction in any medium, provided the original work is properly cited.

\begin{abstract}
In polymer reinforced concrete, the Young's modulus of both polymers and cement matrix is responsible for the detrimental properties of the concrete, including compressive and tensile strength, as well as stiffness. A novel methodology for solving such problems is based on use of ionizing radiation, which has proven to be a good tool for improvement on physical and chemical properties of several materials including polymers, ceramics, and composites. In this work, particles of $0.85 \mathrm{~mm}$ and $2.80 \mathrm{~mm}$ obtained from waste tire were submitted at $250 \mathrm{kGy}$ of gamma radiation in order to modify their physicochemical properties and then used as reinforcement in Portland cement concrete for improving mechanical properties. The results show diminution on mechanical properties in both kinds of concrete without (or with) irradiated tire particles with respect to plain concrete. Nevertheless such diminutions (from 2 to $16 \%$ ) are compensated with the use of high concentration of waste tire particles (30\%), which ensures that the concrete will not significantly increase the cost.
\end{abstract}

\section{Introduction}

The final disposal of used tires is a major environmental problem. In Mexico, it is estimated that only $10 \%$ of the 30 million disposed tires are recycled. The landfills where they are disposed represent a severe risk of fire and a health hazard due to the presence of noxious fauna such as rats, cockroaches, flies, and mosquitoes which can be infectious $[1,2]$.

The most common method to dispose waste tires is to burn them for vapor, heat, or electricity $[3,4]$. The usage of waste tires as alternative fuel in cement furnaces is generalized across the US and Europe [5]. However, these practices result in the generation of organic and inorganic compounds such as zinc oxide $(\mathrm{ZnO})$ and zinc sulfide $(\mathrm{ZnS})$, in hydrocarbon gas, aromatic volatile compounds, liquids formed by heavy and light oils, and all these byproducts which are highly polluting [6].

Another approach for the application of waste tires includes hot bituminous mixes as pneumatic dust for the agglutinative modification in asphalt pavements [7-9]. This application has been more or less effective, but not enough for reducing the reserves of waste tires, since these novel technologies are more expensive than conventional methods 
[10]. An alternative option is to use them as substitute of fine or coarse aggregate in concrete. Their characteristics can improve mechanical properties of concrete as strength and modulus of elasticity, instead of those achieved by sand or stone.

Concrete is one of the most important materials in the construction industry around the world, not only for its cost, but also for its properties as well as its readiness for forming before it hardens which include resistance to climate and durability, among others. However, concrete has a great impact in the environment, it requires great amounts of natural resources for its production (sand, gravel, and water), and the cement generation produces large amounts of carbon dioxide which is discharged in the atmosphere. In fact, it is estimated that cement industry is responsible for the emission of one million tons of $\mathrm{CO}_{2}$ to the atmosphere [11].

In order to reduce the ecological impact, many efforts have been made for reducing the consumption of nonrenewable resources in the production of concrete; one of these is the production or addition of recycled materials into the mixture in substitution of the common aggregates, taking care of the final quality, that include parameters as resistance, modulus of elasticity, and durability, among others [12].

When adding particles to concrete formation, internal stresses are produced and they promote sooner cracking and subsequent failure, which can be avoided with the control of the particle sizes. Early studies pointed out that elastomeric particles can reduce propagation of cracks, show increment in tensile strength, and have capacity in energy absorption [13].

One advantage of the rubber particles is concerning to energy absorption through to ultrasonic waves, in order to benefit the concrete elasticity. However, differences in the Young's modulus between rubber particles and concrete matrix, besides concentration of rubber particles into concrete, could promote great deformations when applying loads and thus progressive diminution of the mechanical properties. Other properties are concerning for concrete workability, including diminution of slump and increment of air content when increasing the elastomeric concentration, which promotes a low unit weight [14].

The use of recycled materials ensures that the product will not significantly increase in cost because is considered as waste, and there is not a specific final use for it. However, recycling of tire rubber is a practice currently industrialized which need follow the current regulations and avoid the pollution caused by a wrong disposal $[15,16]$.

The main aim of this study is the use of waste tire particles and gamma radiation for improvement of mechanical properties of concrete, which open several possibilities in research areas with great benefits, in order to ensure economic earnings in the context of sustainable development, by solving environmental pollution problems.

\section{Experimental}

2.1. Design and Manufacture of Concrete. All mixes were elaborate with Portland cement CPP-30R-RS (according to ASTM C 150 cement type II), natural sand, gravel, and water.
The objective with the mix of these components was obtained $24.5 \mathrm{MPa}$ in compression strength at 28 days of curing, according to ACI 211.1 standard. Moreover, it was added waste tire particles of different sizes in function of the availability of the commercial mesh (sieve). In this case, 20 and 7 meshes correspond to $0.85 \mathrm{~mm}$ and $2.80 \mathrm{~mm}$, respectively; thus, we have an approximate waste particle size ratio of $1: 3$.

Sieved of coarse aggregate (gravel) and fine aggregate (sand) was according to ASTMC136-06 standard. While the unit weight and the moisture content were according to ASTMC29/C29M-09 and ASTM C566-13, respectively, while the saturated surface-dry specific gravity, apparent specific gravity, and water absorption of gravel and sand were determined according to ASTM C127 and ASTM C128 standards.

Physical properties of the components are shown in Table 1 . The sieve analyses of fine and coarse aggregates are shown in Tables 2 and 3.

2.2. Irradiation Procedure. Irradiation at $250 \mathrm{kGy}$ of two different waste tire particle sizes $(0.85 \mathrm{~mm}$ and $2.8 \mathrm{~mm})$ was performed with an irradiator Gammabeam 651-PT loaded with ${ }^{60}$ Co pencils, located at the Institute of Nuclear Sciences (ICN) of the National Autonomous University of Mexico. The irradiation rate was $4 \mathrm{kGy} / \mathrm{h}$. After that the irradiated particles were mixing with concrete components, and finally the mix was casting in molds.

2.3. Mechanical Tests. Concrete specimens were tested after 28 days of curing time. Testing tolerance allowed was 28 days \pm 12 hours according to ASTM C/192 M-00 standard. Compressive strength evaluation was carried out in a universal testing machine Controls 047H4 (Milano, Italy) with capacity of $2000 \mathrm{kN}$, while flexural strength was carried out in an flexural testing machine Elvec 72-4 with capacity of $10 \mathrm{kN}$. The pulse velocity evaluation was carried out with an ultrasonic pulse velocity tester Controls 58E0048 with transmitter and receiver head $(54 \mathrm{kHz})$ and pulse rate of $1 / \mathrm{s}$.

2.4. Mixing, Casting, and Curing Specimens. The concrete mixtures were prepared in a laboratory mixer with capacity of $265 \mathrm{dm}^{3}$. In the first stage dry aggregates (fine and coarse), waste tire particles, and cement were mixed with addition of $85 \%$ of water. In a second stage, after mixing by one minute, $15 \%$ of water was added. Finally, all batches were mixed for a total time of 5 minutes in order to prevent fresh concrete from segregation.

After mixing, the concrete specimens were molded. For each concrete mixture, ten specimens were casting in cylindrical molds of $150 \mathrm{~mm}$ diameter and $300 \mathrm{~mm}$ height, as well as two beams of $150 \times 150 \times 600 \mathrm{~mm}$. After 24 hours, they were placed in a controlled temperature room at $23.0 \pm 2.0^{\circ} \mathrm{C}$ and $95 \%$ of relative humidity. Cured process was performed in accordance with ASTM C511 standard.

The component concentrations of the concrete are shown in Table 4. Regarding the manufactured concrete replacing sand by waste tire particles, two different waste tire particle sizes were used [ $2.8 \mathrm{~mm}$ (mesh 7) and $0.85 \mathrm{~mm}$ (mesh 20)], as 
TABle 1: Physical properties of components of concrete.

\begin{tabular}{lcccc}
\hline Component & $\begin{array}{c}\text { Specific gravity } \\
\left(\mathrm{g} / \mathrm{cm}^{3}\right)\end{array}$ & $\begin{array}{c}\text { Water } \\
\text { absorption }(\%)\end{array}$ & $\begin{array}{c}\text { Loose unit } \\
\text { weight }\left(\mathrm{kg} / \mathrm{m}^{3}\right)\end{array}$ & $\begin{array}{c}\text { Compact unit } \\
\text { weight }\left(\mathrm{kg} / \mathrm{m}^{3}\right)\end{array}$ \\
\hline Gravel & 2.35 & 3.59 & 1367 & 1278 \\
Sand & 2.12 & 11.87 & - & 1443 \\
Tire rubber $(2.80 \mathrm{~mm})$ & 1.04 & - & - & - \\
Tire rubber $(0.85 \mathrm{~mm})$ & 1.35 & - & - & - \\
Cement & 3.10 & - & - \\
Water & 1.00 & - & - \\
\hline
\end{tabular}

TABLE 2: Sieve analysis of sand (fineness modulus $=3.7$ ).

\begin{tabular}{lcccc}
\hline Sieve & Size $(\mathrm{mm})$ & Retained $(\mathrm{g})$ & \% retained (individual) & \% retained (cumulative) \\
\hline 4 & 4.75 & 81 & 4.07 & 4.07 \\
8 & 2.36 & 212 & 10.66 & 14.74 \\
16 & 1.18 & 285 & 14.34 & 29.07 \\
30 & 0.60 & 402 & 20.22 & 49.30 \\
50 & 0.30 & 671 & 33.75 & 83.05 \\
100 & 0.15 & 312 & 15.69 & 98.74 \\
& Bottom tray & 25 & 1.26 & 100.00 \\
\hline
\end{tabular}

TABLE 3: Sieve analysis of gravel (maximum size $=40 \mathrm{~mm}$ ).

\begin{tabular}{lcccc}
\hline Sieve & Size $(\mathrm{mm})$ & Retained $(\mathrm{g})$ & \% retained (individual) & \% retained (cumulative) \\
\hline 1 & 25.0 & 300 & 7.65 & 7.65 \\
$3 / 4$ & 19.0 & 1200 & 30.61 & 38.27 \\
$1 / 2$ & 12.5 & 1040 & 26.53 & 64.80 \\
$3 / 8$ & 9.5 & 240 & 6.12 & 70.92 \\
4 & 4.7 & 800 & 20.41 & 91.33 \\
& Bottom tray & 340 & 8.67 & 100.00 \\
\hline
\end{tabular}

well as three different concentrations of them: 10, 20, and 30\% by volume. The mix code was labeled as Mix-ConcentrationMesh; for example, M10-7 specimens means "Mix with $10 \%$ of waste tire of mesh size 7." The water/cement ratio was kept constant at 0.54 .

The unit weights of concretes are shown in Figure 1. For concretes with nonirradiated waste tire particles different behaviors are observed: (a) the values decrease progressively when adding higher concentration of tire particles. The lowest value is $9 \%$ minor with respect to concrete without tire particles (namely, "control concrete" by us). (b) All concretes have lower values with respect to control concrete $\left(1954 \mathrm{~kg} / \mathrm{cm}^{3}\right)$. (c) The values for concrete with waste particles of $2.8 \mathrm{~mm}$ are higher than those with $0.85 \mathrm{~mm}$. In fact the values decrease because waste tire particles are light, and since they have porous aggregates, air content is increased in concrete mixtures generating low unit weight. This fact agrees with a previous research in which the air content in concrete increases when using bigger rubber particles [17].

In the case of concretes with irradiated waste tire particles, different behaviors are noted. (a) The values decrease when the particle concentration increase. (b) At the difference of the results for concrete with nonirradiated particles, now the higher values are for concrete with tire particles of
$0.85 \mathrm{~mm}$. (c) All values are bigger than those for the control concrete. The highest value is $5 \%$ higher than those for control concrete.

When adding irradiated particles, the concrete shows a reduction in measures (contractions), which was observed during the calculus of volume. With higher particle sizes lower contractions were found in consequence lower unit weight.

\section{Results}

3.1. Compressive Strength. Compressive strength values of concretes are shown in Figure 2. The compressive strength values vary as a function of size and concentration of waste tire particles. For concrete with nonirradiated waste tire particles, the following behaviors are observed. (a) The values decrease progressively according to the particle concentrations which increase. For control concrete, the compressive strength is $24.1 \mathrm{MPa}$, which is bigger than those for all concrete (ranging from 5.2 to $21.4 \mathrm{MPa}$ ); being the highest value for concrete with $10 \%$ of particles of $2.8 \mathrm{~mm}$, such value is $11 \%$ lower than those for control concrete. (b) With respect to the particle size, the compressive strength values are higher for concretes with particles of $2.8 \mathrm{~mm}$ than those with 
TABLE 4: Components of concrete $\left(1 \mathrm{~m}^{3}\right)$.

\begin{tabular}{lcccccc}
\hline Mix code & Waste tire $(\mathrm{col} \%)$ & Waste tire $(\mathrm{kg})$ & Portland cement $(\mathrm{kg})$ & Sand $(\mathrm{kg})$ & Gravel $(\mathrm{kg})$ & Water $(\mathrm{kg})$ \\
\hline M0 & 0 & 0 & 337.1 & 758.5 & 662.6 & 286.3 \\
M10-7 & 10 & 36.2 & 337.1 & 596.4 & 758.5 & 278.4 \\
M20-7 & 20 & 72.4 & 337.1 & 530.1 & 758.5 & 270.6 \\
M30-7 & 30 & 108.7 & 337.1 & 463.8 & 758.5 & 262.7 \\
M10-20 & 10 & 47.2 & 337.1 & 596.4 & 758.5 \\
M20-20 & 20 & 94.5 & 337.1 & 530.1 & 758.5 & 278.4 \\
M30-20 & 30 & 141.7 & 337.1 & 463.8 & 758.5 & 270.6 \\
\hline
\end{tabular}

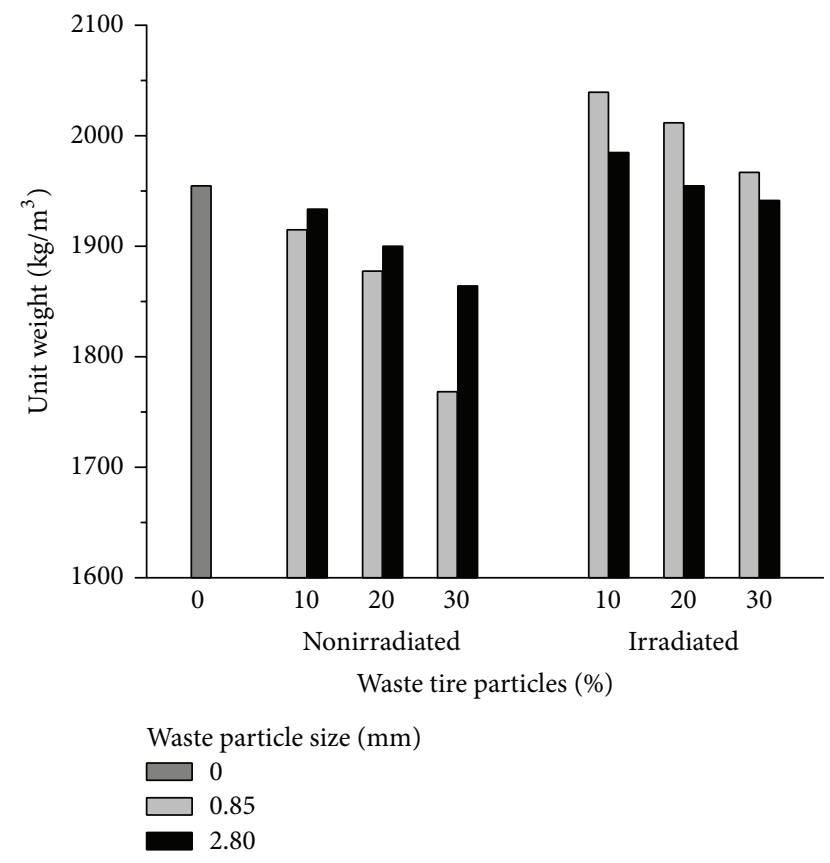

FIGURE 1: Unit weight of concrete with waste tire particles.

$0.85 \mathrm{~mm}$. When increasing the waste particles concentration and adding large particles, more air content is obtained which may cause microcracking and in consequence lower compressive values.

For concrete with waste irradiated tire particles, the compressive strength values follow similar behaviors. (a) The values decrease when increasing the particle concentrations. The values range from 7.4 to $17.5 \mathrm{MPa}$; being the highest value for concrete with $10 \%$ of particles of $2.8 \mathrm{~mm}$, such value is $27 \%$ lower with respect to control concrete. (b) The concretes with particles of $2.8 \mathrm{~mm}$ have bigger values than those with $0.85 \mathrm{~mm}$. (c) The concretes with $20 \%$ or $30 \%$ of particles have higher values when comparing to concrete with nonirradiated particles. Thus, it is more convenient using bigger size particles instead of lower ones.

3.2. Splitting Tensile Strength. Splitting tensile strength values of concretes are shown in Figure 3. For concrete with nonirradiated waste tire particles, the following behaviors are observed. (a) The values decrease when increasing the

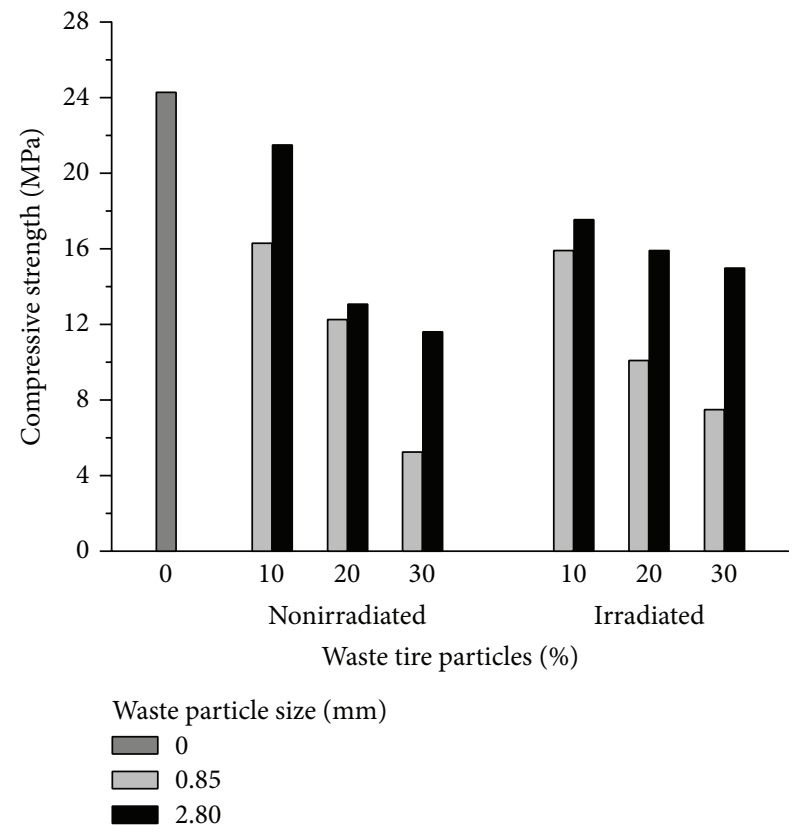

FIGURE 2: Compressive strength of concrete with waste tire particles.

concentration of particles. The values vary from 0.7 to 1.8 $\mathrm{MPa}$; being the highest value for concrete with $10 \%$ of particles of $2.8 \mathrm{~mm}$, this value is $6 \%$ minor than those for control concrete. (b) Concretes with particles of $2.8 \mathrm{~mm}$ have higher values than those with $0.85 \mathrm{~mm}$.

For concrete with irradiated waste tire particles, the splitting tensile strength also decreases when increasing the concentration of particles. The values range from 0.7 to 1.4 $\mathrm{MPa}$; being the highest value for concrete with $10 \%$ of particles of $2.8 \mathrm{~mm}$, it is $27 \%$ minor than those for control concrete. Moreover, higher values are seen for concrete with particles of $2.8 \mathrm{~mm}$. As seen in Figure 1 for compressive strength values, in the case of tensile strength, a similar behavior is observed: the values for concrete with $20 \%$ or $30 \%$ of particles are higher than those for concrete with nonirradiated particles.

For both kinds of concrete, with irradiated or nonirradiated waste particles, the compressive and splitting tensile strength behavior is similar because the induced stresses 


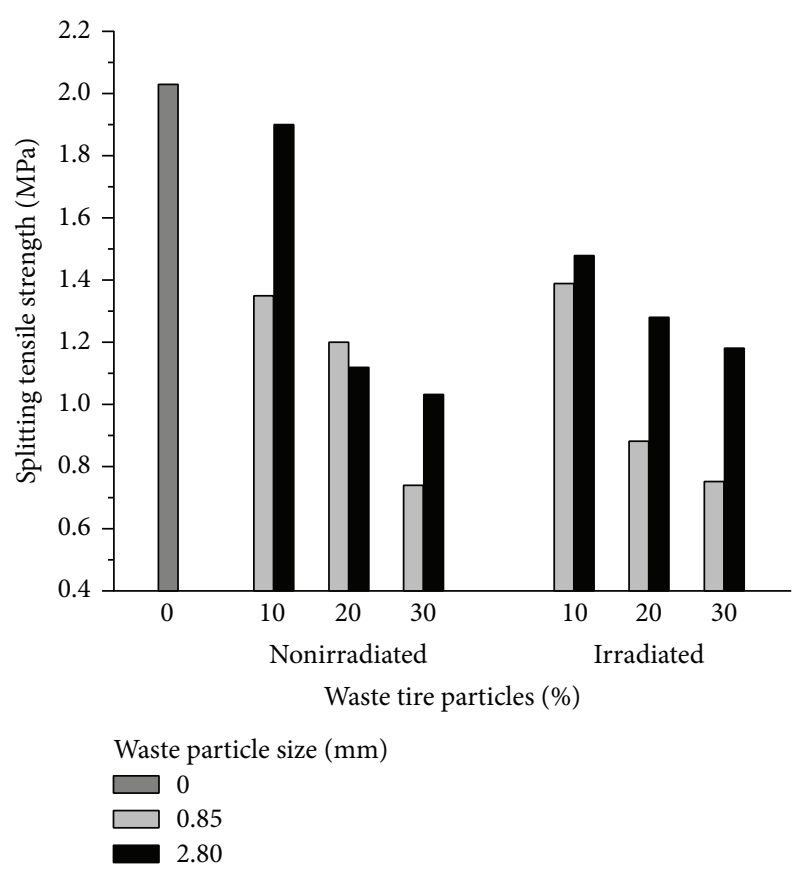

FIGURE 3: Splitting tensile strength of concrete with waste tire particles.

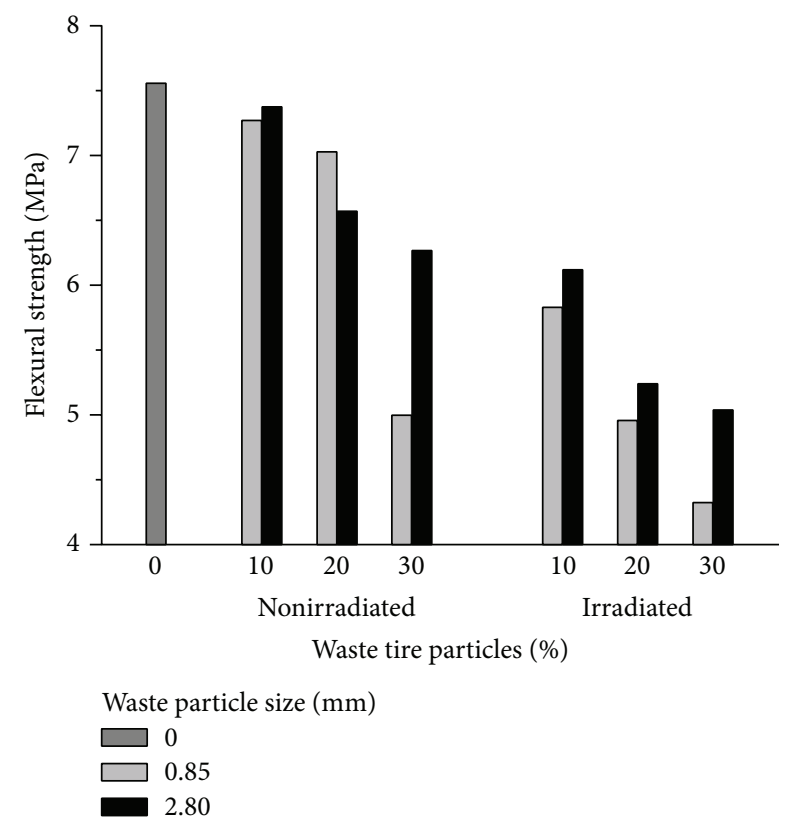

FIGURE 4: Flexural strength of concrete with waste tire particles.

generated in the specimens are of the same nature, they act in the direction of the load application axis.

3.3. Flexural Strength. The flexural strength values are shown in Figure 4. For concrete with nonirradiated waste particles, the values range from 4.9 to $7.3 \mathrm{MPa}$. The results indicate that (a) There is a progressive diminution of values when increasing the concentration of particles. The highest value is

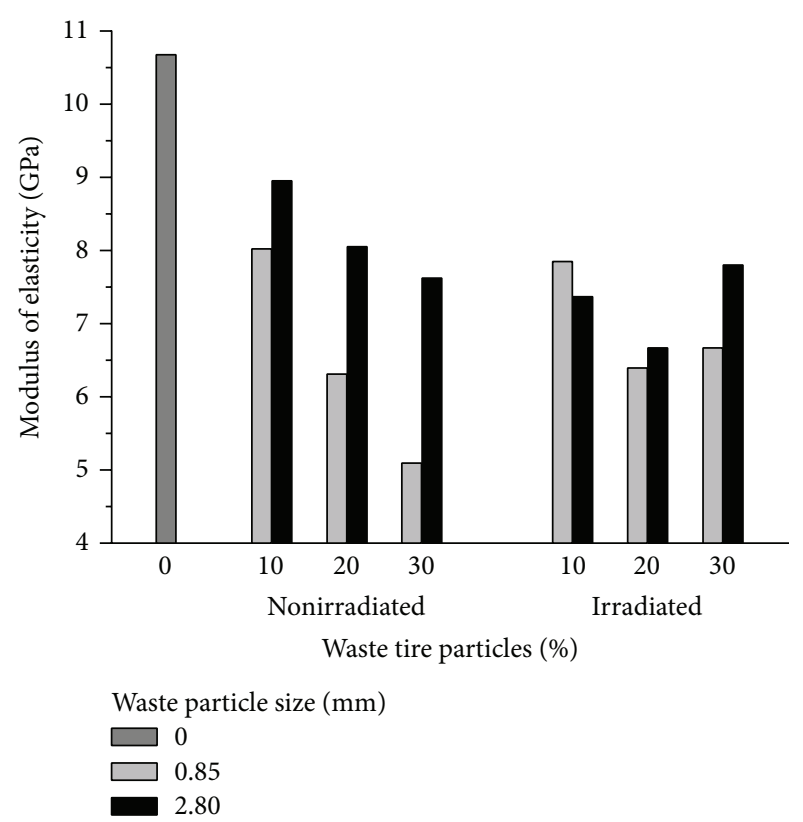

FIGURE 5: Modulus of elasticity of concrete with waste tire particles.

obtained by concrete with $10 \%$ of particles, which is $2 \%$ minor than those obtained for control concrete. (b) Variations in terms of the particle size are observed, and higher values are for concretes with $10 \%$ and $30 \%$ and particles of $2.8 \mathrm{~mm}$ for concrete with $20 \%$ but with particles of $0.85 \mathrm{~mm}$.

For concrete with irradiated particles, the flexural strength values range from 4.3 to $6.1 \mathrm{MPa}$; such values are lower when comparing with concrete with nonirradiated particles. The flexural strength values decrease when increasing the concentration of particles; and the values are bigger for concretes with particles of $2.8 \mathrm{~mm}$.

3.4. Modulus of Elasticity. The modulus of elasticity values is shown in Figure 5. The highest value corresponds to control concrete, namely, 10.6 GPa. For concrete with nonirradiated waste tire particles, the values range from 5.0 to $8.9 \mathrm{GPa}$. The highest value (obtained by concrete with $10 \%$ of particles of $2.8 \mathrm{~mm}$ ) is $16 \%$ minor with respect to control concrete. As other mechanical features discussed in previous sections, the modulus of elasticity values follows similar behaviors. (a) The values decrease when increasing the concentration of particles. (b) Also, concrete with particles of $2.8 \mathrm{~mm}$ has higher modulus of elasticity values when comparing to those with $0.85 \mathrm{~mm}$.

For concrete with irradiated particles, modulus of elasticity values ranges from 6.4 to $7.8 \mathrm{GPa}$, which are higher than those for concrete with nonirradiated particles. Special attention is taken on these concretes because variations in the modulus of elasticity are observed. (a) Two "stages" are identified: the first one consists in a diminution of the values for concretes with $10 \%$ and $20 \%$ of particles, and the second consists in an increment for concrete with $30 \%$ of particles. (b) In terms of the particle size, concrete with $10 \%$ of particles has the highest values when adding particles of $0.85 \mathrm{~mm}$, and 


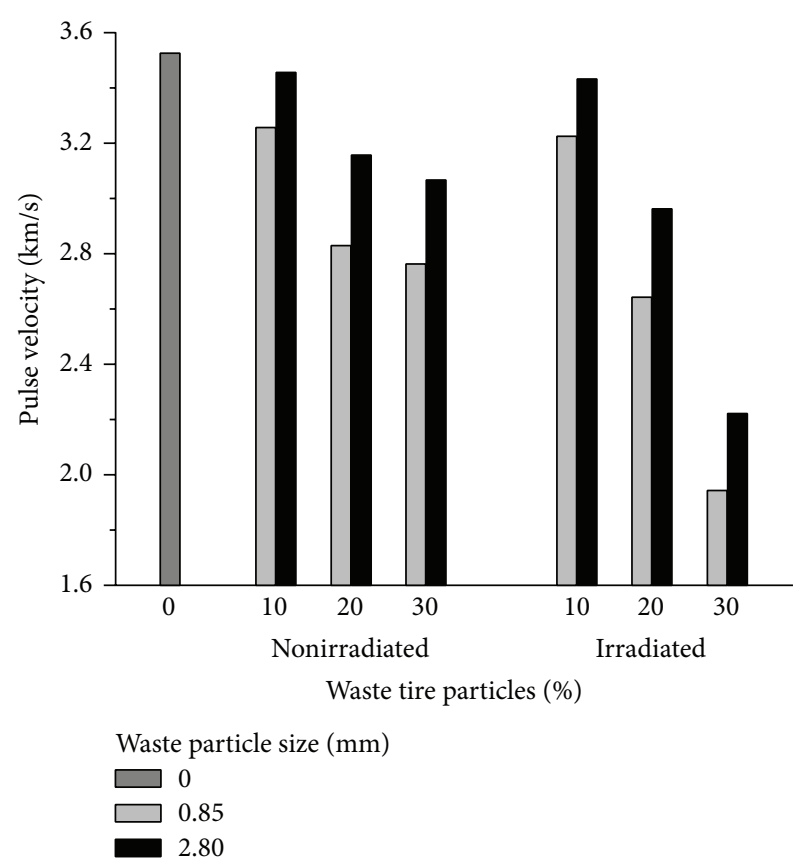

FIGURE 6: Pulse velocity of concrete with waste tire particles.

conversely highest values for concretes with $20 \%$ or $30 \%$ of particles are done when using particle sizes of $2.8 \mathrm{~mm}$.

According to mechanical concepts, there is a correlation between the compressive strength and the modulus of elasticity values [18] and also between modulus of elasticity and the unit weight. In both cases, waste particles contribute to higher deformations, lower crack formation, and lower unit weights in concrete, which results in lower modulus of elasticity.

3.5. Pulse Velocity. In Figure 6 the ultrasonic pulse velocities of concrete are shown. The highest value corresponds to control concrete, namely, $3.5 \mathrm{~km} / \mathrm{s}$. For concrete with nonirradiated particles, the values range from 2.7 to $3.4 \mathrm{~km} / \mathrm{s}$; it means that the highest value is $2 \%$ minor with respect to control concrete. Moreover, the values follow the same behaviors. (a) The values decrease when increasing the concentration of waste tire particles. (b) The values are bigger for concrete with particles of $2.8 \mathrm{~mm}$.

In the case of concrete with irradiated waste particles, the behavior does not change, and they follow the same behavior as concrete with nonirradiated particles.

\section{Conclusions}

The mechanical properties of concrete depend on the waste tire particle sizes and their concentration. Compressive and tensile strength values decrease due to waste tire particles, because they promote stress concentration zones, as well as generation of tensile stresses into concrete, resulting in a fast cracking and soon failure. Nevertheless, when applying gamma radiation to waste tire particles, in some cases, improvements on mechanical properties are found. Even so, it seems that the best option is, in all cases, for concrete with
$10 \%$ of nonirradiated waste tire particles and size of $2.8 \mathrm{~mm}$. Concrete with irradiated particles can support up to $30 \%$ of tire particles, making it possible to reduce the final cost of the concrete.

\section{Conflict of Interests}

The authors do not have a direct financial relation or conflict of interests with the commercial identities mentioned in this submitted paper, and the commercial trademarks such as Controls and Elvec only were reported to guarantee the reproducibility, in the same conditions, of the different tests.

\section{Acknowledgments}

The authors acknowledge the National Council for Science and Technology of México (CONACYT) for the scholarship support for Eduardo Sadot Herrera-Sosa for the achievement of this research and the Environmental Sciences Graduate Program of Universidad Autónoma del Estado de México (UAEM).

\section{References}

[1] R. K. Dhir, M. C. Limbachiya, and K. A. Paine, Recycling and Use of Tyres, Thomas Telford, London, UK, 2001.

[2] M. R. Taha, A. S. El-Dieb, and M. Nehdi, "Recycling tire rubber in cement-based material," Concrete With Recycled Materials, ACI Committee 555, 2008.

[3] H. Briodsky, "The important role retreads can play in reducing the scrap tyre problem," in Recycling and Use of Tyres, R. K. Dhir, M. C. Limbachiya, and K. A. Paine, Eds., pp. 57-62, Thomas Telford, London, UK, 2001.

[4] K. M. Brown, R. Cummings, J. R. Mrozek, and P. Terrebonne, "Scrap tire disposal: three principles for policy choice," Natural Resources Journal, vol. 41, no. 1, pp. 9-22, 2001.

[5] R. W. Davies and G. S. Worthinton, "Use of scrap tyre as a fuel in the cement manufacturing process," in Recycling and Use of Tyres, R. K. Dhir, M. C. Limbachiya, and K. A. Paine, Eds., pp. 93-106, Thomas Telford, London, UK, 2001.

[6] R. Mis-Fernandez, J. A. Azamar-Barrios, and C. R. RiosSoberanis, "Characterization of the powder obtained from wasted tires reduced by pyrolysis and thermal shock process," Journal of Applied Research and Technology, vol. 6, pp. 95-105, 2008.

[7] S. N. Amirkhanian, "Utilization of crumb rubber in asphaltic concrete mixtures-south Carolinas's experience," Research Report, South Carolina Department of Transportation, 2001.

[8] F. J. Navarro, P. Partal, F. Martínez-Boza, and C. Gallegos, "Influence of crumb rubber concentration on the rheological behavior of a crumb rubber modified bitumen," Energy and Fuels, vol. 19, no. 5, pp. 1984-1990, 2005.

[9] R. G. Nelson and A. S. M. M. Hossain, "An energetic and economic analysis of using scrap tyres for electricity generation and cement manufacturing," in Recycling and Use of Tyres, R. K. Dhir, M. C. Limbachiya, and K. A. Paine, Eds., pp. 119-127, Thomas Telford, London, UK, 2001.

[10] C.-T. Chiu, "Use of ground tire rubber in asphalt pavements: field trial and evaluation in Taiwan," Resources, Conservation and Recycling, vol. 52, no. 3, pp. 522-532, 2008. 
[11] V. M. Malhotra, "Role of supplementary cementing materials in reducing greenhouse gas emissions," in Concrete Technology for a Sustainable Development in the 21st Century, O. E. Gjorv and K. Sakai, Eds., pp. 226-235, E \& FN Spon, London, UK, 2000.

[12] C. Meyer, "Concrete as a green building material," in Proceedings of the 3rd International Conference on Construction Materials (ConMat '05), Vancouver, Canada, 2005.

[13] G. L. Nacif, T. H. Panzera, K. Strecker, A. L. Christoforo, and K. Paine, "Investigations on cementitious composites based on rubber particle waste additions," Materials Research, vol. 16, pp. 259-268, 2013.

[14] R. Siddique and T. R. Naik, "Properties of concrete containing scrap-tire rubber-an overview," Waste Management, vol. 24, no. 6, pp. 563-569, 2004.

[15] J. Karger-Kocsis, "Waste tyre rubber-what to do next?" eXPRESS Polymer Letters, vol. 7, p. 406, 2013.

[16] C. R. Rios-Soberanis, S. Wakayama, T. Sakai, J. A. RodriguezLaviada, and E. Pérez-Pacheco, "Manufacture of partially biodegradable composite materials based on PLA-Tires powder: process and characterization," International Journal of Polymer Science, vol. 2013, Article ID 514951, 8 pages, 2013.

[17] G. Skripkiunas, A. Grinys, and M. Dauksys, "Using tires rubber waste for modification of concrete properties," in Sustainable Construction Materials and Technologies, Y. M. Chun, P. Claisse, T. R. Naik, and E. Ganjian, Eds., pp. 85-90, Taylor \& Francis, London, UK, 2007.

[18] American Concrete Institute Committee 318: ACI 318-05/318R05, "Building Code Requirements for Structural Concrete and Commentary," 2005. 

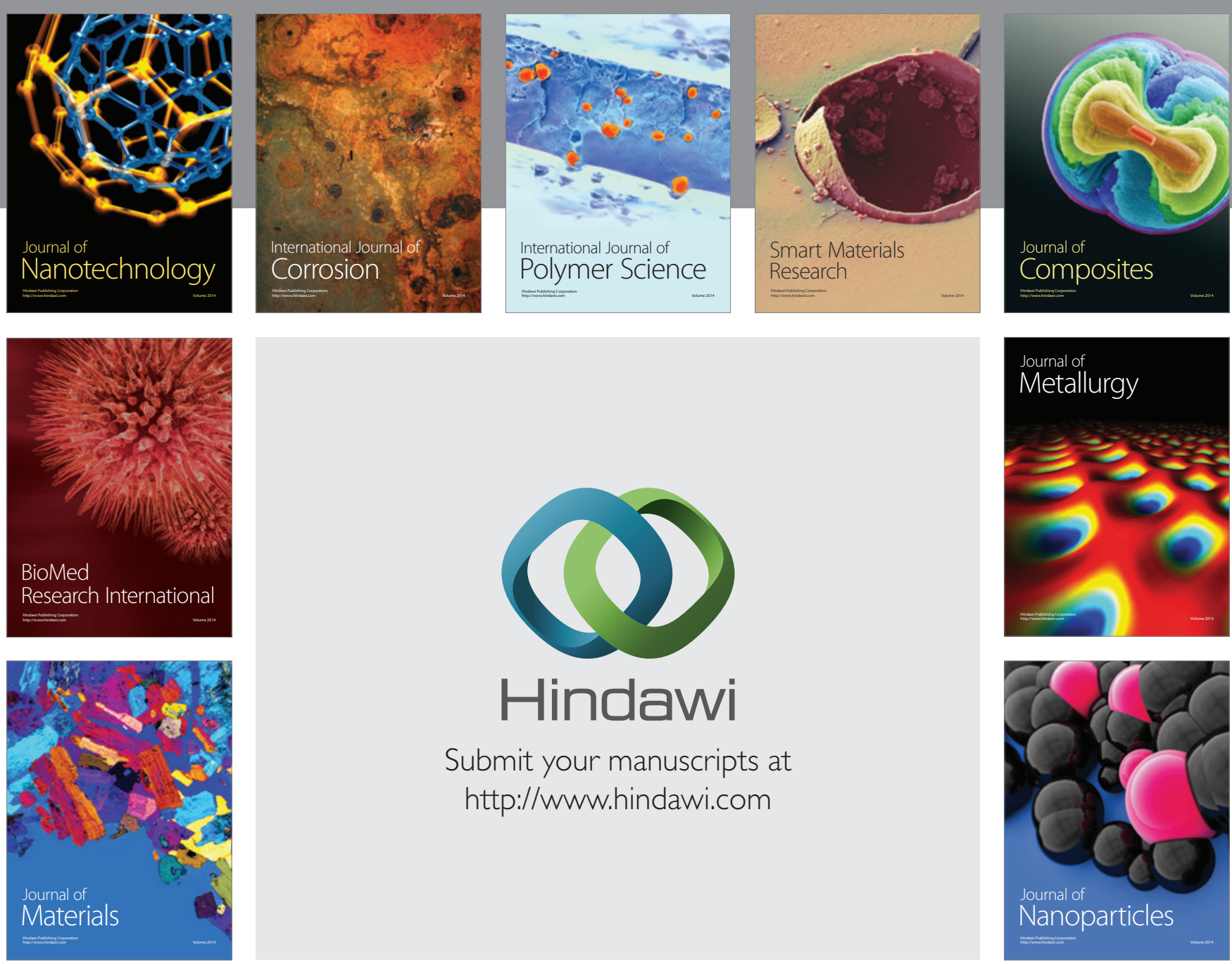

Submit your manuscripts at http://www.hindawi.com
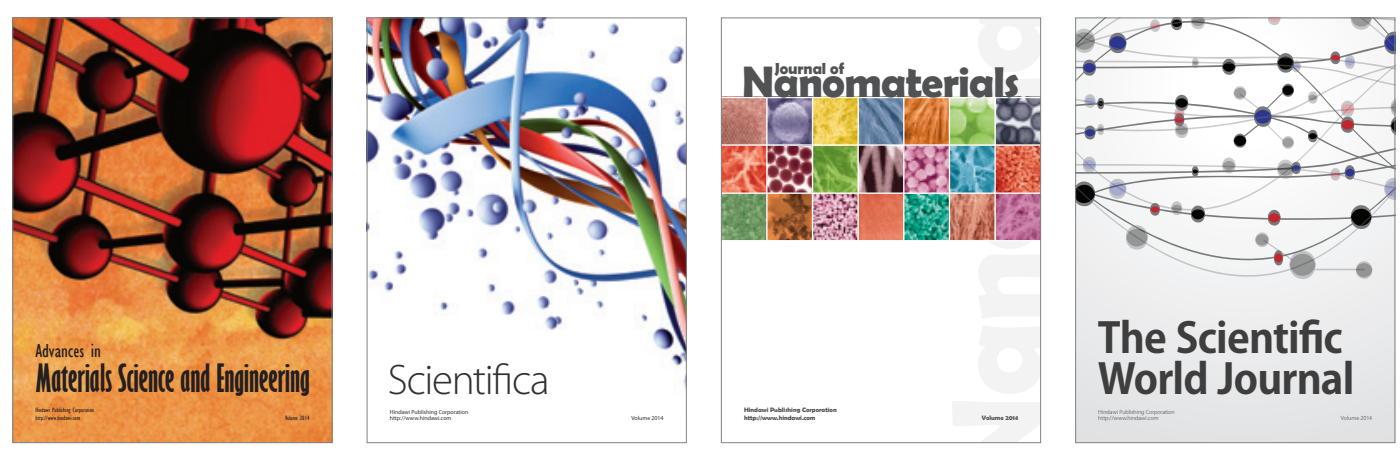

\section{The Scientific World Journal}
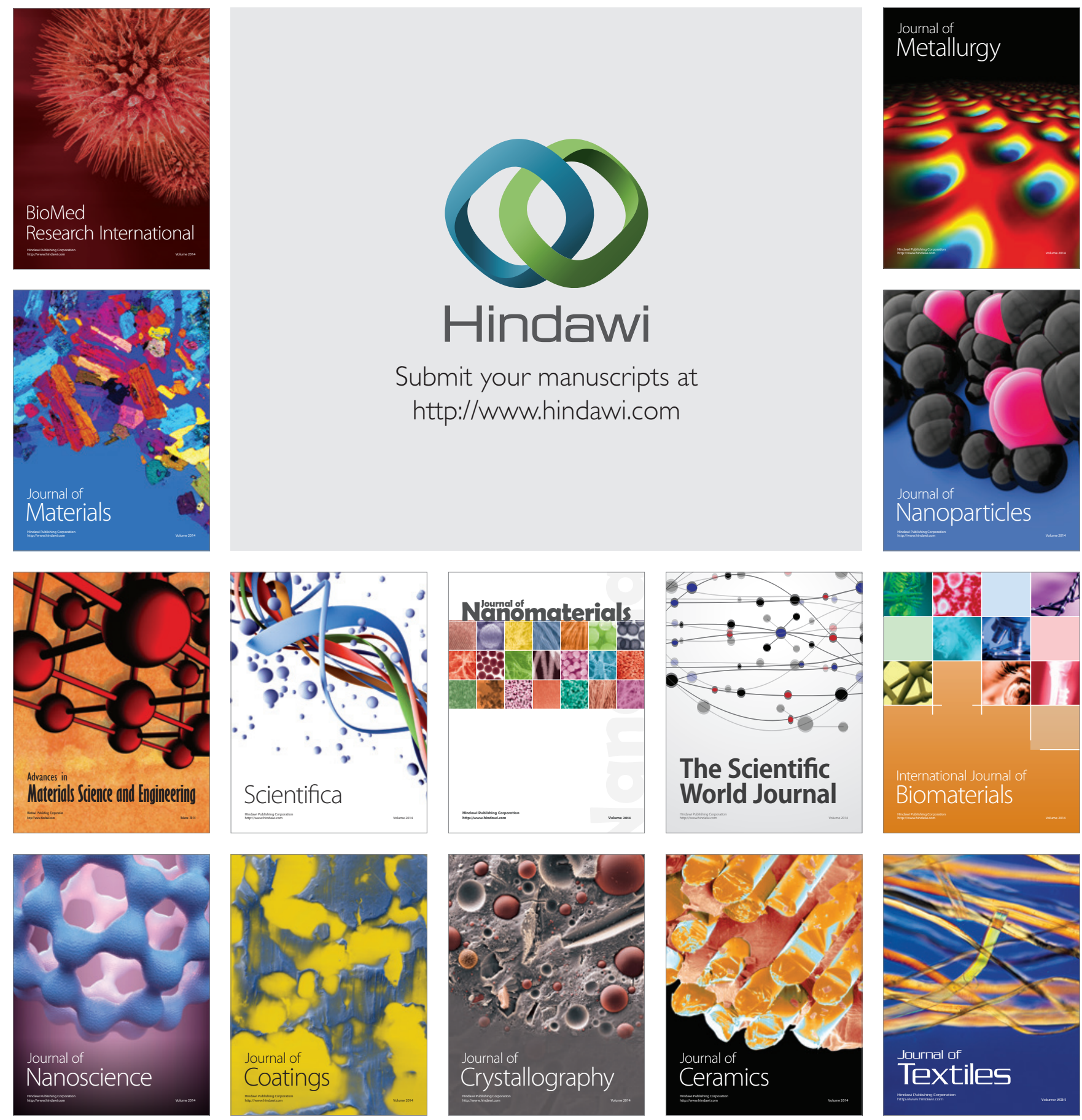